Universidad de Guadalajara

Derecho Global. Estudios sobre Derecho y Justicia Año 2021, Vol. VI. Número 17, Marzo - Junio, pp 167-193, ISSN: 2448-5128 e-ISSN: 2448-5136 https://DOI.org/10.32870/dgedj.v6i17.351

PABLO ANDRÉS BONILLA HERNÁNDEZ

Universida de San Carlos, Guatemala justiciaconstitucionalguate@gmail.com

\title{
LA FIGURA DE DECLATORIA DE PERSONA NON GRATA EN LA DIPLOMACIA: EXPERIENCIAS DE LA PRÁCTICA RECIENTE EN GUATEMALA
}

DECLARATION OF PERSONA NON GRATA IN DIPLOMACY: EXPERIENCES OF RECENT PRACTICE

IN GUATEMALA

Recibido: 20/04/2020 Aceptado: 17/10/2020 


\title{
RESUMEN
}

El presidente guatemalteco Jimmy Morales Cabrera (electo para el periodo 2016-2020) utilizó, en un par de ocasiones, la figura de declaratoria de "persona non grata" para expulsar a ciertas personalidades diplomáticas como el Comisionado de la Comisión Internacional contra la Impunidad en Guatemala (CICIG) y el Embajador del Reino de Suecia. En ambos casos, se generaron diversas y encontradas reacciones mediáticas, políticas y estrictamente jurídicas. Este artículo analiza la figura de la declaratoria de persona non grata, tanto en el ámbito del derecho diplomático como en el contexto guatemalteco reciente, de forma particular, su regulación en el sistema jurídico doméstico. Así como las discrepancias mayores observadas en la conceptualización y ejercicio en ambos sistemas,

\section{Palabras Clave:}

Derecho Diplomático, Diplomacia, Persona non grata, Corte Constitucional.

\begin{abstract}
Guatemalan President Jimmy Morales Cabrera (elected for the period 2016-2020) used on a couple of occasions, the figure of declaration of "persona non grata" to certain diplomatic personalities such as the Commissioner of the International Commission against Impunity in Guatemala (CICIG) and the Ambassador of the Kingdom of Sweden. In both cases, media, political and legal reactions were generated. This article discusses the declaratory of persona non grata in the recent Guatemalan context, both in the field of the diplomatic law and Guatemalan legal system, observing major discrepancies in conceptualization and exercise.
\end{abstract}

\section{KEYWORDS:}

Diplomatic Law, Diplomacy, Persona non grata, Constitutional Court. 
La figura de declatoria de personas non grata en la diplomacia: experiencias de la práctica reciente en Guatemala

Sumario: I. Introducción. II. La figura de la declaratoria de Persona NON GRATA EN El DERECho INTERNACIONAL. III. LA PRÁCTICA RECIENTE en Guatemala. IV. La persona non grata en el Derecho InTERnACIONAL y EN El Derecho Guatemalteco. V. Conclusiones. BiBLIOGRAFÍA.

\section{INTRODUCCIÓN}

E $\mathrm{s}$ un hecho que los Estados conservan una competencia exclusiva en un por el Derecho Internacional, pueden reaccionar conforme a sus políticas nacionales y adoptar unilateralmente decisiones que produzcan efectos jurídicos en sus relaciones con los demás Estados (Bondía, 2004, pp. 13-14) y con más precisión, pudiera decirse, más allá de sus relaciones con otros Estados, en todas sus relaciones con los demás sujetos de Derecho Internacional. Como una de las múltiples modalidades de los actos unilaterales de los Estados se ubica la figura de declaratoria de persona non grata, que si bien a principios de este siglo era calificada de "rara" (Aust, 2005, p. 122), no es ahora una figura aislada o inusual pues entre diciembre de 2016 y abril de 2018, 29 países declararon como persona non grata a más de trescientos funcionarios diplomáticos que debieron abandonar el territorio del país receptor (Flores Troche, 2019, p. 132.). Una razón de su poco ejercicio radicaba en la fuerte relación o amistad entre los dos Estados tanto a nivel de gobierno como de sociedad; o por la sensación psicológica de no querer ofender a un superpoder del que puede depender de una manera $\mathrm{o}$ el otro (Hendrapati, 2014), pero también es un hecho innegable que algunos Estados han excedido deliberadamente los límites impuestos por el derecho diplomático, especialmente los artículos 41 y 42 de la Convención de Viena de 1961 e intervenido de desagradable manera en los asuntos internos de otros Estados debido a su conocimiento de la limitada sanción que podría imponerse a sus representantes, es decir, mediante la expulsión del territorio a través de la declaración persona non grata (Fakhoury, 2017). 
El presidente guatemalteco Jimmy Morales, en un mensaje emitido el domingo 27 de agosto de 2017, divulgó la declaratoria de persona "non grata" del señor Iván Velásquez Gómez, en su calidad de Comisionado de la Comisión Internacional contra la Impunidad en Guatemala (CICIG) ordenando a su vez que "abandonara inmediatamente" la República de Guatemala, fundando su acción en el hecho de que como presidente de Guatemala tenía la facultad de declarar "non grato" a un diplomático sin tener la obligación de exponer los motivos de dicha decisión, pero que, sin embargo, había decidido explicarlo por lo que argumentó que el Comisionado se había excedido en sus funciones al inmiscuirse en los asuntos internos del Estado de Guatemala (Prensa Libre TV, 2017, Órbita TV, 2017) ${ }^{1}$. La situación descrita generó una serie de interpretaciones, tanto de los órganos de control de constitucionalidad como de la academia, para contradecir la supuesta facultad presidencial empleada por Morales, concluyendo que el acto había sido ilegal y, por lo tanto, debía considerarse nulo.

No es este el espacio para el análisis del papel que desempeñó la CICIG en sus doce años de existencia, ni se enfoca en evaluar su trabajo que desde sus orígenes han sido motivo de polarización de la opinión pública guatemalteca. No se analizarán tampoco el contexto político y las razones que manejaron los medios de comunicación como las causas que motivaron al Ejecutivo de Guatemala para utilizar esta figura que le provee el Derecho Diplomático, mucho menos se pretende tomar partido con alguno de los actores de la escena gubernamental guatemalteca. Simplemente se hace un análisis de la figura de la declaratoria de persona non grata a la luz del Derecho Internacional para cotejar su concepto a las conductas de quienes intervinieron en el ejercicio de la misma durante la administración del presidente Morales.

Evidentemente, el derecho a declarar a los agentes diplomáticos o consulares persona non grata ha resultado controvertido en su ejercicio precisamente por su carácter discrecional (d'Aspremont, 2009). Sin embargo, es una facultad de la que están investidos los órganos de las relaciones internacionales en un Estado, la cual está reconocida y codificada en el Derecho Internacional y, por

\footnotetext{
${ }^{1}$ El exsecretario general de Naciones Unidas, Javier Pérez de Cuéllar (1997) es de la idea de que si bien se determinó que no había obligación del Estado argumentar las razones que le motivaban a declarar non grata a un funcionario diplomático, en casos evidentes, procedería una declaración fundamentada.
} 
lo tanto, inexcusable a través de una norma doméstica. En este contexto, este artículo aborda primeramente el uso y codificación de la figura de la declaratoria de persona non grata en el Derecho Internacional; enseguida se tratan dos casos recientes de la práctica de esta figura en Guatemala, particularmente, las ejercidas por el presidente Jimmy Morales para analizar las facultades que como Jefe de Estado posee en la materia; si es aplicable hacerlo respecto del Comisionado de la CICIG al expresarse que ésta no es parte de la estructura de Naciones Unidas, los fundamentos de derecho interno para invalidar estos actos del Ejecutivo guatemalteco para, finalmente, exponer las consideraciones finales al respecto.

\section{LA FIGURA DE LA DECLARATORIA DEPERSONA NON GRA- TA EN EL DERECHO INTERNACIONAL.}

Hay coincidencia en cuanto a considerar que, desde el punto de vista del Derecho Internacional, la declaratoria de persona non grata puede ser considerada una modalidad de los actos unilaterales del Estado puesto que existe concomitancia en sus elementos con la definición que establece el Proyecto de artículos sobre los actos unilaterales de los Estados presentado por el Relator Especial del tema en sus diferentes informes, en los cuales se le ha conceptualizado como "una manifestación de voluntad inequívoca del Estado, formulada con la intención de producir efectos jurídicos en sus relaciones con uno o varios Estados o una o varias organizaciones internacionales y que es del conocimiento de ese Estado o esa organización internacional" (Bondía, 2004, p. 205).

La inviolabilidad es una de las manifestaciones más antiguas del Derecho Internacional, y protege a la persona del embajador, su persona, su vivienda y sus documentos. En general, la inmunidad diplomática se considera absoluta e integral. Sin embargo, implica ciertas restricciones necesarias y lógicas (Witiw, 1988) y, se podría añadir, también sanciones. Una de ellas es la declaratoria de persona non grata que consiste en el señalamiento público del incumplimiento y el respectivo mandato de abandonar el territorio del país huésped. La expulsión de extranjeros normalmente se llama deportación y se basa en los supuestos 
determinados por la legislación doméstica, pero la declaración de persona non grata, que se se utiliza para un agente diplomático, puede tener su origen en el abuso de las inmunidades diplomáticas de índole político (extralimitarse de sus funciones o entrometerse en asuntos domésticos) o personal (que se circunscriben a violaciones a la norma local por parte del diplomático en cuestión). En este último caso, la inmunidad diplomática contra el enjuiciamiento no se extiende a la inmunidad de expulsión. En gran medida, la expulsión elimina la necesidad de ocuparse por el posible abuso de la condición diplomática porque la expulsión se utiliza como preventivo. No hay necesidad de anticipar la defensa de la inmunidad como lo hay en un proceso (Witiw, 1988).

\section{El desarrollo de la declaratoria de non grata en el Derecho Diplomático}

La expulsión de funcionarios diplomáticos está permitida por el Derecho Internacional. El exsecretario general de Naciones Unidas, Javier Pérez de Cuéllar (1997) señala que el Estado huésped tiene el derecho de protegerse contra abusos de los privilegios e inmunidades y de toda violación flagrante de ciertas reglas básicas de convivencia que rigen en su territorio. La posibilidad de expulsión de un diplomático fue considerada desde mucho tiempo atrás: en su libro El Espíritu de las Leyes, Montesquieu rememoraba que "El derecho de gentes ha establecido que los príncipes reinantes se envíen embajadores; la razón fundada en la naturaleza de la cosa, no consiente que el embajador de un soberano dependa del soberano del país en que ostenta su representación, ni de sus tribunales; son la palabra del príncipe a quien representan, y esta palabra ha de ser libre. No han de encontrar ningún obstáculo que les impida desempeñar su misión... Si abusan de su carácter representativo, se les pone coto despidiéndolos. También puede acusárseles ante su soberano, que así sería su juez o su cómplice" (Montesquieu, 1845 , p. 207, cursivas añadidas).

Fue el 20 de febrero de 1928, durante la VI Conferencia Panamericana celebrada en La Habana, cuando se adoptó la Convención sobre Funcionarios Diplomáticos, que en su artículo 8 estableció "Ningún Estado podrá acreditar sus funcionarios diplomáticos ante los demás Estados, sin previo arreglo con éstos", es decir, aquí hay referencia a lo que se conoce como beneplácito o plácet y, 
en el segundo párrafo, se señala que "Los Estados pueden negarse a admitir un funcionario diplomático de los otros, o, habiéndolos admitido ya, pedir su retiro, sin estar obligados a expresar los motivos de su resolución", es decir, establece la figura de persona non grata en lo que puede considerarse el primer antecedente de su codificación. Esta Convención fue suscrita por Guatemala, pero no llegó a ratificarla (Convención Funcionarios Diplomáticos, 1928).

El 21 de noviembre de 1947, se aprobó la Convención sobre los Privilegios e Inmunidades de los Organismos Especializados como la Resolución 79 (II), que en su Artículo VI, Sección 21, reconoce "los privilegios, inmunidades, exenciones y facilidades que se otorgan conforme al Derecho Internacional a los enviados diplomáticos" y en el artículo VII, denominado "Abuso de privilegios", específicamente en la Sección 24, señala que, "ante el abuso de un privilegio o de una inmunidad reconocidos en dicho instrumento, se realizarán consultas e incluso se podría acudir a la Corte Internacional de Justica”. Esta Convención establece que los representantes de los miembros o las personas que disfruten de la inmunidad diplomática no serán obligados a abandonar el país si no es conforme al procedimiento diplomático aplicable a los enviados diplomáticos acreditados en ese país, por lo que se remite al cumplimiento de un procedimiento establecido por el derecho doméstico si este existe ${ }^{2}$.

Es sabido que el tema de las relaciones diplomáticas fue considerado como uno de los temas denominados "maduros" para su codificación y de los primeros enlistados para los trabajos de la Comisión de Derecho Internacional (CDI) creada por Naciones Unidas en 1948. El Relator Especial del tema, Emil Sandström, presentó el borrador inicial para la codificación del tema en 1955, aunque el Reporte de la CDI a la Asamblea General (A/3623) de 1957, aclara que "el borrador sólo trata de las misiones diplomáticas permanentes", pero reconoce que las relaciones diplomáticas entre Estados asumen también otras formas que generalmente se conoce bajo el título de la "diplomacia ad hoc", que cubre a los

\footnotetext{
${ }^{2}$ En las negociaciones de Viena sobre la Convención de Relaciones Diplomáticas (décimo tercera sesión del 14 de marzo de 1961), el delegado español José Sebastián Erice y O’Shea intervino para señalar que "la declaración de una persona como non grata en algunos países requiere una decisión unánime del Consejo de Ministros calificando su procedimiento de demasiado formal, demasiado solemne y complicado" (United Nations, 1962b, p, 101).
} 
enviados itinerantes, conferencias diplomáticas y misiones especiales enviadas a un Estado para propósitos limitados y que la CDI consideró otras formas de diplomacia. El parágrafo 14 reconoce que aparte de las relaciones diplomáticas entre los Estados existen las relaciones entre Estados y organizaciones internacionales, pero señala que la cuestión de los privilegios e inmunidades de las propias organizaciones generalmente son regidas por convenciones especiales.

El borrador de lo que, a la postre, se aprobaría como la Convención de Viena sobre Relaciones Diplomáticas, al abordar el tema de la declaratoria de persona non grata, proponía: "El Estado receptor podrá, en cualquier momento, comunicar al Estado acreditante que el jefe u otro miembro del personal diplomático de la misión es persona non grata o no es aceptable. En tal caso, el Estado acreditante retirará entonces a esa persona o pondrá término a sus funciones en la misión, según proceda" (Sandström, 1950, p. 133). A esta redacción se adicionaría la propuesta de Francia de señalar "sin tener que exponer los motivos de su decisión" y la propuesta belga de que se agregara que toda persona podría ser declarada non grata o no aceptable antes de su llegada al territorio del Estado receptor. El entonces artículo 6 conteniendo las enmiendas propuestas, se aprobó por unanimidad en la sesión del 29 de mayo de 1958 y se convertiría en el artículo 8. En Viena, el artículo 8 (persona non grata) fue adoptado por 65 votos a favor, ninguno en contra y 6 abstenciones. En la versión final de la Convención la declaratoria de persona non grata quedo con el numeral 9.

Es así que el vigente artículo 9 de la Convención de Viena sobre Relaciones Diplomáticas (1961) establece que “1. El Estado receptor podrá, en cualquier momento y sin tener que exponer los motivos de su decisión, comunicar al Estado acreditante que el jefe u otro miembro del personal diplomático de la misión es persona non grata, o que cualquier otro miembro del personal de la misión no es aceptable. El Estado acreditante retirará entonces a esa persona o pondrá término a sus funciones en la misión, según proceda. Toda persona podrá ser declarada non grata o no aceptable antes de su llegada al territorio del Estado receptor. 2. Si el Estado acreditante se niega a ejecutar o no ejecuta en un plazo razonable las obligaciones que le incumben a tenor de lo dispuesto en el párrafo 1, el Estado receptor podrá negarse a reconocer como miembro de la misión a la persona de que se trate" (Travieso, 1998, p. 269). 
Nunca quedó establecido el mecanismo que debía emplearse para su ejercicio. Si bien, en principio, la declaración de persona non grata es notificada al Estado acreditante por los canales diplomáticos tradicionales (el Ministerio de Relaciones Exteriores lo comunica a su contraparte - en ocasiones incluso después de haber efectuado el anuncio oficial - vía nota verbal), la difusión pública de tal decisión puede ser hecha por representantes del Estado de distinta jerarquía (Flores Troche, 2019, p. 147). Estas disposiciones tienen su correlativo enunciado en la Convención de Viena sobre Relaciones Consulares de 1963.

Por otra parte, en el tema de Responsabilidad de los Estados, el Sr. Willem Riphagen, Relator Especial sobre la materia en la CDI, al presentar su tercer informe sobre el contenido, las formas y los grados de la responsabilidad internacional argumentó que "En una posición intermedia entre las obligaciones que proceden del Derecho Internacional consuetudinario y las que se derivan de tratados están las normas de derecho consuetudinario que se aplican a las relaciones entre los Estados y que son, por decirlo así, 'provocadas' o ‘completadas' por algún tipo de consentimiento entre esos Estados. El proceso de consentimiento crea entonces un status del que se derivan derechos y obligaciones entre los Estados. Ejemplo típico de esto son las normas de derecho consuetudinario sobre relaciones diplomáticas". Recordó la sentencia de la CIJ en el caso de los Rehenes de la Embajada norteamericana en Teherán en la cual el cuerpo de normas jurídicas del derecho diplomático es considerado como un régimen autónomo y que, por lo tanto, a la violación de una obligación en esta esfera por el Estado que envía puede contraponerse únicamente lo que en esencia constituye una suspensión parcial (que podría incluir la declaración de persona non grata) o total (ruptura de relaciones diplomáticas) de las relaciones, comparable a la exceptio non adimpleti contractas del derecho de los tratados (United Nations, 1984, p. 29).

Es importante destacar que, por una parte, en el Preámbulo de la Convención de Viena de 1961 sobre Relaciones Diplomáticas, se establece que los Estados Partes en la Convención afirman que "las normas del Derecho Internacional consuetudinario han de continuar rigiendo las cuestiones que no hayan sido expresamente reguladas" en las disposiciones de la señalada Convención y; por otra parte, la Corte Internacional de Justicia ha establecido que las normas del Derecho Diplomático, en definitiva, constituyen un régimen autónomo que, por 
un lado, establece las obligaciones del Estado receptor en cuanto a facilidades, privilegios e inmunidades a concederse a las misiones diplomáticas $\mathrm{y}$, por otra parte, prevé su posible abuso por los miembros de la misión, especificando los medios a disposición del Estado receptor para contrarrestar tal abuso (ICJ, 1980, párr. 86), esto es, la declaratoria de persona non grata. En este sentido, la Corte añade que más allá de ese remedio para hacer frente a los abusos de la función diplomática por miembros de una misión, un Estado receptor tiene en sus manos un remedio más radical si los abusos de sus funciones por los miembros de una misión alcanzan graves proporciones, esto es, romper relaciones diplomáticas con un Estado acreditante y pedir el cierre inmediato de la misión ofensora. (ICJ, 1980, párr. 85).

También debe señalarse que la Conferencia de Viena de 1975 que adoptó Convención de Viena sobre la Representación de los Estados en sus Relaciones con las Organizaciones Internacionales de Carácter Universal no incluyó alguna disposición relativa a la declaración de persona non grata o a la expulsión de representantes por parte del Estado huésped. "Ello, entre otras cosas, enfrentó a los Estados huéspedes de las principales organizaciones internacionales, por un lado, y al resto de los Estados por otro" (Pérez de Cuéllar, 1997, p. 177). Al final, se aprobó en una parte del artículo 77, una disposición estableciendo que "en caso de infracción grave y manifiesta a la legislación penal del Estado huésped, el Estado que envía retirará a la persona de que se trata y pondrá término a las funciones que ejerza en la misión". Igualmente se señala que "el Estado que envía tomará la misma medida en caso de injerencia grave y manifiesta en los asuntos internos del Estado huésped".

En la opinión del que fuera el representante de Chile en la Conferencia de Viena, Luis Melo Lecaros (2004) la declaración de persona non grata es un recurso extremo que, en general, se origina por razones de orden personal, que se tramita con la mayor discreción y de forma verbal y por excepción se deja constancia escrita. Que es muy diferente cuando los motivos de dicha declaratoria son de motivo político interno o internacional en cuyo caso la publicidad es importante consecuencia del incidente, que adquiere mayores proporciones y lo magnifica. En cuanto a la forma, normalmente, las manifestaciones de voluntad se realizan por escrito, pero nada impide que sea hecha de forma oral, con los mismos efectos 
La figura de declatoria de personas non grata en la diplomacia: experiencias de la práctica reciente en Guatemala

que un instrumento escrito. No obstante, las declaraciones hechas de forma oral, generalmente, después son consignadas por escrito (Bondía, 2004, pp. 129-130).

\section{LA PRÁCTICA RECIENTE EN GUATEMALA}

El presidente de Guatemala, Jimmy Morales, utilizó, durante su mandato, la figura de Declaratoria de persona non grata en dos ocasiones: respecto del Comisionado de la CICIG y, posteriormente, del Embajador del Reino de Suecia. Tuvo diferente motivación en cada uno de los casos, pero un mismo fundamento: la atribución que el Derecho Internacional concede a los sujetos encargados de las relaciones exteriores de un Estado. Cierto es también que, en estos dos casos, la intervención judicial, por conducto del Tribunal Constitucional, frenó la ejecución de los actos con fundamento en normas de carácter doméstico.

\section{El Comisionado de la CICIG "non grato"}

En una descripción de los hechos, se puede señalar que, el domingo 27 de agosto de 2017, Guatemala conoció un mensaje que el entonces mandatario Morales difundió a través del canal de gobierno y redes sociales. La esencia del mensaje señalaba: "El Presidente de la República y jefe de Estado de Guatemala con fundamento en la Constitución Política (...) por los intereses del pueblo de Guatemala, el fortalecimiento de un Estado de Derecho y la institucionalidad, declaro non grato al señor Iván Velásquez Gómez en su calidad de comisionado de la Comisión Internacional Contra la Impunidad en Guatemala y ordeno que abandone de inmediato la República de Guatemala" (Prensa Libre TV, 2017).

Este acto significaba la ruptura con el titular de la CICIG y, en consecuencia, el trabajo de esta Comisión quedaba lastimado, pues se trata de un acuerdo bilateral entre Naciones Unidas y la República de Guatemala, es decir, el establecimiento de la CICIG derivó del Acuerdo entre la Organización de Naciones Unidas y el Gobierno de Guatemala firmado en Nueva York, el 12 de diciembre de 2006, con el propósito de "apoyar, fortalecer y coadyuvar a las instituciones del Estado de 
Guatemala encargadas de la investigación y la persecución penal de los delitos presuntamente cometidos con ocasión de la actividad de los cuerpos ilegales de seguridad y aparatos clandestinos de seguridad; así como en la determinación de sus estructuras, actividades, formas de operación y fuentes de financiamiento, promoviendo tanto la desarticulación de dichas organizaciones como la sanción penal de los partícipes de los delitos cometidos".

El Acuerdo tuvo su origen en el compromiso del Gobierno de Guatemala establecido en el Acuerdo Global de Derechos Humanos de 22 de marzo de 1994 para combatir los cuerpos ilegales y los aparatos clandestinos de seguridad. En virtud de dicho instrumento, a la CICIG se le dotó de personalidad jurídica y quedó integrada por un Comisionado designado por el Secretario General de la Organización de Naciones Unidas, así como por personal especializado y una Secretaría. Su presupuesto, según el propio Acuerdo (artículo 7), se sufragaría con contribuciones voluntarias de la comunidad internacional. En el último de los Considerandos del Preámbulo quedó establecido que la CICIG no sería un órgano de las Naciones Unidas, sino que funcionaría solamente de conformidad con los términos del Acuerdo.

Retomando los hechos que originaron la declaratoria de persona non grata del Comisionado de la CICIG, el 22 de agosto de 2017, el periodista José Rubén Zamora Marroquín posteó en sus redes sociales un artículo denominado "Un llamado a la cordura", en el cual informaba que una anunciada visita del presidente a la sede de Naciones Unidas tenía el propósito entrevistarse con el Secretario General de Naciones Unidas para demandarle la salida inmediata del Comisionado de la CICIG. Agregaba que ante una casi segura negativa del funcionario, "el presidente Morales ha sido aconsejado para declarar no grato al comisionado Velásquez y expulsarlo de Guatemala" (Zamora, 2017). En la mañana del 27 de agosto de 2017, se concretó lo que hasta ese momento era rumor y el entonces presidente Jimmy Morales dio a conocer el mensaje ya referido.

Más tarde, ese mismo día, Morales volvió a salir a los medios para dar a conocer las razones de dicha decisión, señalando que actuaba motivado por los intereses del pueblo de Guatemala, que no lo hacía por razones personales ${ }^{3}$.

${ }^{3}$ Los medios guatemaltecos manejaban la versión de que esta decisión estaba motivada por el hecho de que tanto la CICIG como el Ministerio Público habían solicitado un antejuicio contra Jimmy Morales para que 
Declaró que el rumbo de las acciones del señor Velásquez Gómez se estaban alejando del mandato dado a la Comisión y particularmente, lo fundamentó en el hecho de que intentó presionar, por diferentes medios, a los Diputados del Congreso de la República de Guatemala para la aprobación de reformas constitucionales sin dejar que el Congreso discutiera y las aprobara libremente. Que era su deber no permitir presiones ilegítimas, ilegales e inconstitucionales como las que el Comisionado había presuntamente hecho al Órgano Legislativo, alegando la violación del artículo 41 de la Convención de Viena sobre Relaciones Diplomáticas ${ }^{4}$. Que también se excedió y abusó de su mandato al hacer publicaciones en diversos medios sobre acusaciones a ciudadanos guatemaltecos sin observar la garantía constitucional de la presunción de inocencia, derecho de defensa y debido proceso. Finalmente, le acusó de utilizar también a los medios para presionar a jueces y magistrados para que resolvieran o pudieran resolver de manera contraria al ordenamiento jurídico guatemalteco (Órbita TV, 2017).

\section{La resolución y postura de la Corte Constitucional}

La expulsión de Iván Velásquez denunciada por el periodista José Rubén Zamora, advirtió a la opinión pública y, en ese contexto, Elvyn Leonel Díaz Sánchez y Álvaro Montenegro Muralles ${ }^{5}$, presentaron ante la Corte de Constitucionalidad (CC) una acción de amparo para evitar que se expulsara al Comisionado. Posteriormente, hizo lo propio el Procurador de los Derechos Humanos, Jordán

Rodas Andrade. La Corte concedió lugar las acciones a favor de Velásquez y suspendió, de manera provisional, la expulsión.

\footnotetext{
fuera investigado por presuntas transacciones ilegales en su partido, así como el proceso penal que la propia Comisión ya había sometido a Tribunales en contra del hijo y hermano del expresidente.

${ }^{4}$ Muy probablemente se refería a apartado primero que señala "Sin perjuicio de sus privilegios e inmunidades, todas las personas que gocen de esos privilegios e inmunidades deberán respetar las leyes y reglamentos del Estado receptor. También están obligados a no inmiscuirse en los asuntos internos de ese Estado".

${ }^{5}$ Estos abogados fueron los primeros en presentar la acción de amparo, su expediente se menciona en el 4185-2017 y tiene un correlativo previo que es el 4179-2017. El Procurador fue el último que presentó el Amparo, pero fue el que la Corte tomó para resolver el expediente.
} 
La CC resolvió otorgar el amparo provisional solicitado sobre el acto que se señaló como reclamado, fundándose en que la Ley de Amparo, Exhibición Personal y de Constitucionalidad, establece (artículo 28) que: "Deberá decretarse de oficio la suspensión provisional del acto, resolución o procedimiento reclamado, entre otros, en los casos siguientes: c) Cuando la autoridad o entidad contra la que se interponga el amparo esté procediendo con notoria ilegalidad o falta de jurisdicción o competencia". En ese sentido, la CC presupuso que existía una "notoria ilegalidad" que se desprendía del hecho de que el documento carecía de las solemnidades formales que la Constitución Política de la República de Guatemala, en sus artículos 182, segundo párrafo, y 194, inciso c) prescriben para la validez de la decisión, toda vez que el Presidente debe actuar siempre con los Ministros, en Consejo o separadamente con uno o más de ellos y en lo que refiere a la segunda disposición constitucional que es relativa a los Ministros, éstos deben refrendar los decretos, acuerdos y reglamentos dictados por el Presidente de la República que tengan que ver con la materia de su despacho para que tengan validez. Al carecer de estas formalidades, la CC declara "nulo de pleno derecho" el acto presidencial.

Pero luego la CC “estima necesario invocar" lo dispuesto en el artículo 12 del Acuerdo que crea la CICIG, que establece que "Toda controversia entre las partes relacionada con la interpretación o con la aplicación del presente Acuerdo se resolverá por negociación entre las partes o por cualquier otro medio de solución mutuamente convenido" y, señala traerlo a referencia porque "esta norma orienta el hecho de que la decisión contenida en el acto reclamado resulta unilateral y desatiende la regla de solución prevista en el precepto transcrito, lo que hace que dicha decisión resulte nula de pleno derecho también por ese motivo" (CC, 2017, agosto 29). Resulta particularmente llamativo el hecho de que la CC actúe como si estuviera enterada y completamente al tanto de que el Ejecutivo no había hecho uso de lo dispuesto por el numeral 12 del Acuerdo. La ilegalidad identificada por la CC tiene su origen en el documento que el presidente de la República de Guatemala, autoridad denunciada en el amparo, presentó como informe circunstanciado. La CC aduce suspender la decisión presidencial de declarar non grato al Comisionado de la CICIG, toda vez que "se concretó la amenaza que constituye el acto reclamado en el amparo, hecho notorio y público, por las 
declaraciones que comunicó por medios públicos el presidente de la República de Guatemala como autoridad denunciada" (CC, 2017, agosto 29).

La Magistrada Presidenta de la CC, Dina Josefina Ochoa Escribá, otorgó un voto razonado disidente en el auto del expediente 4179-2017, fundamentándolo en los artículos 182 y 183 de la Constitución de Guatemala que otorgan al presidente la calidad de Jefe de Estado y la potestad de dirigir la política exterior y las relaciones internacionales, respectivamente, por lo que a su juicio, el presidente sí tiene la facultad de declarar persona non grata a la persona que se encuentre a cargo de la CICIG, puesto que el acuerdo respectivo le confiere, en su artículo 10, la calidad de agente diplomático. Disiente de la decisión de que otorgar el amparo provisional descanse en el artículo 12 del Acuerdo que establece que cualquier controversia relativa a la interpretación o aplicación del mismo, deba resolverse por negociación entre las partes, porque no era la cuestión a discusión, sino la facultad de poder declarar al Comisionado como persona non grata, mencionando también que resultaba aplicable la norma de Derecho Internacional que establece que una parte no puede invocar las disposiciones de su derecho interno como justificación del incumplimiento de un tratado, refutando con ello la falta de formalidad al acto presidencial de conformidad con el derecho guatemalteco.

\section{El Embajador sueco}

En mayo de 2018, nueve meses después del incidente con el Comisionado de la CICIG, la Cancillería guatemalteca, a través de nota diplomática, pidió a Suecia cambiar a su embajador en Guatemala, Anders Kompass, bajo el argumento de "injerencia". Suecia fue el segundo aportante para el funcionamiento de la CICIG, después de EE.UU. De 2009 a 2018 los suecos contribuyeron con 33 millones de dólares para la operación de la Comisión.

La decisión del gobierno se generó a partir de una intervención del diplomático sueco en la que expresó textualmente: "Decir que la cultura es mala no está muy lejos de decir que la gente es mala y no creo que sea correcto tampoco un buen incentivo para alcanzar los cambios. Por esto es más correcto decir que el problema son las instituciones públicas disfuncionales, no la gente. Los cambios institucionales deben ser de una naturaleza tan integral que no solo 
cambian la percepción de un individuo de cómo jugar las reglas del juego, en una sociedad corrupta sino también, y quizá principalmente, hay que crear la percepción de que otros en su situación también estén dispuestos a cambiar su comportamiento. Esto en otras palabras exige una medicina fuerte, y creo que en Guatemala esta medicina se llama CICIG. Muchas gracias" (Montepeque, 2018). El gobierno consideró la mención de la frase "sociedad corrupta" estaba dirigida a la de Guatemala y, en consecuencia, determinó que estaba profiriendo una ofensa que, en su criterio, no podía dejarse pasar. En este caso fue la Fundación Myrna Mack ${ }^{6}$ y el abogado Alfonso Carrillo quienes plantearon el proceso de amparo para impedir la expulsión del Embajador sueco. Nuevamente en decisión dividida por tres votos a dos7 , la CC aceptó, el 29 de mayo de 2019, una acción de amparo contra la expulsión de Kompass ordenada por la Ministra de Relaciones Exteriores Sandra Jovel.

En los expedientes de amparo con relación a la declaratoria de persona non grata al Embajador de Suecia, hubo dos votos disidentes, uno de ellos fue el de la Magistrada Presidenta Dina Josefina Ochoa Escribá, quien además de señalar que su postura era estrictamente jurídica y no prejuzgaba el desempeño diplomático del representante de Suecia, argumentaba, en su Resolutivo 11, que consideraba que la CC no podía interferir en el desenvolvimiento, que por uso diplomático, le corresponde, por exclusividad a los órganos estatales correspondientes, es decir, las Cancillerías de los Estados involucrados, señalando "Además, traigo a colación, el artículo 27 de la Convención de Viena sobre Derecho de los Tratados que regula que una parte no podrá invocar las disposiciones de su derecho interno como justificación del incumplimiento de un tratado... Una resolución judicial nacional (como de la que me separo) no puede ni debe desatender un principio de

\footnotetext{
${ }^{6}$ La Fundación Myrna Mack fue creada en 1993 por Helen Mack Chang en memoria de su hermana, una antropóloga asesinada en 1990 por un escuadrón de la muerte de las fuerzas armadas guatemaltecas. Su caso fue objeto de un procedimiento ante la Corte Interamericana de Derechos Humanos que culminó con una sentencia condenatoria para el Estado de Guatemala de fecha 25 de noviembre de 2003. En esta sentencia, el juez mexicano Sergio García Ramírez hace referencia, por vez primera, al llamado "control de convencionalidad" que se ha convertido en un importante paradigma dentro y por fuera del sistema de protección regional de derechos humanos.

${ }^{7}$ Fueron los mismos magistrados (es decir, coinciden) quienes votaron a favor y quienes votaron en contra en el otro expediente del caso CICIG.
} 
carácter diplomático internacional" (CC, 2018b).

En la audiencia de vista pública de fecha 13 de agosto de 2019, el abogado el Ministerio de Relaciones Exteriores, Luis Lam, dijo que la "Corte de Constitucionalidad otorgó un amparo provisional que se considera como una intromisión directa en funciones que le competen con exclusividad al jefe de Estado y presidente constitucional". La expulsión del Embajador, en todo caso, al final no se concretó porque el gobierno de Suecia lo llamó a Consultas ${ }^{8}$ debido "a la situación política en el país y el estado de nuestras relaciones con Guatemala" según informó la ministra de Asuntos Exteriores sueca, Margot Wallström, en un comunicado de 17 de febrero de 2019 (The Local). Kompass siguió ejerciendo su cargo fuera de Guatemala y regresó cuando Morales dejó el poder en enero de 2020 .

\section{LA PERSONA NON GRATA EN EL DERECHO INTERNACIO- NAL Y EN EL DERECHO GUATEMALTECO}

Haciendo un análisis jurídico de la decisión presidencial en relación con la motivación o justificación de la declaración persona non grata, puede establecerse que el Derecho Internacional, particularmente su rama dedicada a la rama diplomática, generó la figura de declaratoria de persona non grata para solventar momentos de tensión entre las autoridades del Estado receptor y funcionarios diplomáticos acreditados ante su gobierno. Es una medida de última instancia, cuando se ha agotado la negociación o ésta ya es inviable. No puede soslayarse que "la declaración de persona non grata generalmente se usa con marcados fines políticos" (Aust, 2005, p. 122), y es cierto también que "contribuye a la escalada de una crisis diplomática" (Flores Troche, 2019, p. 144).

\footnotetext{
${ }^{8}$ Carles Pérez-Desoy i Fage (2013) caracteriza al "Llamado a Consultas" como un peldaño más en la escalada de la relación. Se refiere al Embajador propio, al que el Estado acreditante hace viajar desde el país en el que está acreditado (Estado receptor) hasta su capital, con el objetivo de evacuar consultas con las autoridades. A pesar de su nombre, se trata principalmente de un gesto diplomático, siendo la evacuación de consultas un objetivo menor. La llamada a consultas constituye ya una crisis mayor en una relación bilateral. Puede añadirse que se trata de poner las relaciones en observación. Es una forma de protesta país que un país utiliza cuando se siente inconforme con una situación específica con otro gobierno. Muchas veces es un acto de presión como hecho previo para el rompimiento de relaciones diplomáticas.
} 
Por ser una medida radical que, evidentemente, puede lastimar la relación con la contraparte, algunos gobiernos la evaden o buscan por otros medios su resultado, por ejemplo, en 2011, el entonces presidente de México, Felipe Calderón, con denotada iracundia fustigó al embajador de Estados Unidos, Carlos Pascual, al conocerse algunos de los informes que éste había enviado a su gobierno como parte natural de su función diplomática (filtrados por el portal de Wikileaks). Por la magnitud de la relación bilateral y la delicadeza que impone su tratamiento, Calderón no optó por declararlo non grato, pero sí declaró a la prensa que el escándalo de Wikileaks había dañado la relación bilateral y que se había perdido la confianza en el Embajador. El funcionario diplomático, al saber que había perdido su capacidad de interlocución con el Ejecutivo mexicano (el presidente y sus subalternos) tomó la decisión de renunciar. Al final, el hecho tuvo el mismo resultado que declararlo persona non grata9 .

Por otra parte, el ejercicio de esta figura está reservado a los llamados "órganos de las relaciones internacionales", esto es, Jefes de Estado, Jefes de Gobierno y titulares de las Relaciones Exteriores. Sin embargo, como señala Flores Troche (2019, p. 146), en la práctica diplomática, la forma de los actos tiene una relevancia particular e incluso un contenido político implícito, a tal punto que normalmente se aprecia una preponderancia de este tipo de motivos detrás de estas decisiones. Asimismo, se observa una práctica progresiva de los Estados que motu proprio, sin que exista obligación jurídica, exponen y hacen públicas las razones subyacentes de sus actos unilaterales.

En este sentido, resulta ilustrativo observar la jerarquía del representante estatal que comunicó la decisión de la declaración de persona non grata y el mecanismo que se eligió para notificarla y hacerla del dominio público. En el caso del Comisionado de la CICIG, era de la más alta prioridad del gobierno,

\footnotetext{
${ }^{9}$ El desgaste en la relación bilateral no quedó exento. La Secretaria de Estado, Hillary Clinton, emitió un duro comunicado para patentizarlo. Señaló entonces que "con gran pesar anuncio que el Embajador Pascual nos ha pedido al presidente Obama y a mí que aceptemos su dimisión como nuestro embajador en México", a lo largo del comunicado, la referencia de "Embajador Pascual" se convirtió en "Carlos" (lo cual también tiene un significado diplomático de querer evidenciar la cercanía de la persona), así "Carlos ha transmitido su decisión de regresar a Washington basándose en su deseo personal de asegurar la fuerte relación entre nuestros dos países y de evitar que los asuntos planteados por el presidente Calderón puedan distraer el importante objetivo de promover nuestros intereses bilaterales" (Clinton, 2011).
} 
puesto que fue el presidente quien personalmente hizo los anuncios respectivos. En el caso del Embajador sueco todo lo gestionó la Cancillería, por lo que parece era de menor importancia para el gobierno guatemalteco. Evidentemente, en este último caso, se buscaba generar menor desgaste a la figura presidencial. Debe tomarse en cuenta también que la jerarquía del portavoz de la decisión tiene una vinculación estrecha con la relevancia política que el Estado busca atribuir a la declaración misma (Flores Troche, 2019, p. 148).

Por otra parte, en cuanto a las facultades del ejecutivo guatemalteco para declarar persona non grata a un diplomático en su territorio, al menos en cuanto a los dos casos ya antes abordados, es indispensable para alcanzar un balance final, en primer lugar, reconocer que se está en presencia de situaciones claramente diferenciadas: en el caso del Comisionado, resolver la incógnita pasa necesariamente por cuestionar la naturaleza de la CICIG (para efectos justamente de aplicar o no la Convención de Viena sobre Relaciones Diplomáticas) y, por ende, la calidad o no de diplomático de dicho comisionado. En el otro caso, el Embajador sueco la cuestión es evidente y clara, ya que ocupando éste la calidad de Embajador, resulta incuestionable la aplicación de la Convención de Viena sobre Relaciones Diplomáticas para los efectos de dicha declaratoria.

Ahora bien, respecto a la naturaleza del Comisionado y de la propia CICIG, el Acuerdo respectivo deja en claro que la CICIG no era parte de las Naciones Unidas, de hecho, el último de sus Considerandos hacía ver que "el Secretario General y el Gobierno de Guatemala han celebrado negociaciones para el establecimiento de la CICIG, no siendo un órgano de las Naciones Unidas, sino que funcionará solamente de conformidad con los términos de este Acuerdo" (CICIG, 2006). De ahí que la figura tanto del Comisionado como de la propia CICIG, fuese una figura única, producto de un acuerdo internacional negociado entre las partes.

De dicha cuenta, al no ser parte la CICIG del organigrama de Naciones Unidas, aparentemente no sería aplicable el Artículo 105 de la Carta donde se establece que "la Organización gozará, en el territorio de cada uno de sus Miembros, de las prerrogativas e inmunidades necesarias para la realización de sus fines, y que los representantes de los Miembros de la Organización y que los funcionarios de ésta, gozarán asimismo de las prerrogativas e inmunidades necesarias para ejercer 
con independencia sus funciones en relación con la Organización" (Travieso, 1998, p. 44). Sin embargo, en el acuerdo quedó establecido en el primer apartado del artículo 10 intitulado "Privilegios e inmunidades del Comisionado/a y del personal de la CICIG" que "El Comisionado disfrutará de los privilegios e inmunidades, exenciones y facilidades otorgados a los agentes diplomáticos de conformidad con la Convención de Viena sobre Relaciones Diplomáticas de 1961" (CICIG, 2006) y enlista ciertos privilegios específicos. Esta última disposición fue empleada en otros acuerdos suscritos por Naciones Unidas para establecer tribunales especiales o híbridos. Así, en el Acuerdo entre las Naciones Unidas y el Gobierno de Sierra Leona sobre el establecimiento de un Tribunal Especial para Serra Leona de fecha 16 de enero de 2002, en su artículo 12 refiere que "los jueces, fiscal y secretario del Tribunal disfrutarán de los privilegios e inmunidades, exenciones y facilidades otorgados a los agentes diplomáticos de conformidad con la Convención de Viena sobre Relaciones Diplomáticas de 1961 ” y también hace una lista particular. Igualmente lo señala el Acuerdo entre las Naciones Unidas y el Gobierno Real de Camboya relativo a la persecución bajo el derecho camboyano de los crímenes cometidos durante el periodo de la Kampuchea Democrática del 6 de junio de 2003 y que estableció las llamadas Cámaras Extraordinarias en las Cortes de Camboya (artículo 19 aplicable a funcionarios internacionales). También lo establece el artículo 11 del Acuerdo entre las Naciones Unidas y la República Libanesa sobre el establecimiento de un Tribunal Especial para Líbano de 6 de febrero de 2007.

En virtud de lo anterior, siendo que es el mismo Acuerdo el que cita a la Convención de Viena para aplicarla de forma supletoria en disposiciones particulares, podría interpretarse que también se puede emplear para situaciones no previstas en el Acuerdo, ello sin perjuicio que el artículo 12 permitiera que toda controversia entre las partes relacionada con la interpretación o con la aplicación del Acuerdo se resolviera por negociación entre las partes o por cualquier otro medio de solución mutuamente convenido. En el caso concreto, cae por su propio peso el hecho de que existió de ambas partes ausencia de capacidad por negociar y arreglar el conflicto de manera diplomática, y por ello la declaratoria fue la salida que tomó finalmente el Ejecutivo guatemalteco. 
Refuerza esta interpretación la perspectiva de las propias Naciones Unidas ya que, según comunicó su portavoz en Nueva York, Stéphane Dujarric (2017), el Secretario General estaba sorprendido de la declaración del presidente Jimmy Morales, al tiempo que pedía que se tratara a Velásquez con "respeto debido a sus funciones como funcionario internacional". Esto parece ser consecuente también con la propia autopercepción de la Comisión ya que, en el mismo tenor, la página electrónica de la CICIG (todavía en línea a octubre de 2020) empleaba el logotipo de Naciones Unidas en su diseño.

Finalmente y como separata a este apartado, podría comentarse que la figura se ha empleado por algunos gobiernos para declarar non grata a personas que no ostentan función diplomática alguna, pero para hacer una manifestación política o mediática, así por ejemplo el actor Brad Pitt fue declarado persona non grata por el gobierno chino debido a su participación como protagonista en la película "Siete años en el Tíbet"; o está el caso del Concejo Municipal de Panamá que declaró, en marzo de 2011, persona "non grata" al magnate y a la postre presidente estadounidense Donald Trump, por haber señalado que Washington entregó "estúpidamente" el Canal interoceánico a los panameños a cambio de nada.

Se ha señalado (Villagrán, 2017) que al otorgar al Presidente la capacidad de declarar a un jefe de misión como non grato, se vulnera el derecho del Secretario General de nombrar a su mejor criterio al Comisionado de la CICIG, lo cual también es falso en la medida que los Estados al asentir la Convención de Viena reconocen dicha facultad que no es posible refutar. Los ejemplos contemporáneos son abundantes ${ }^{10} \mathrm{e}$, incluso, podría ejercerse antes de la llegada del nominado, lo cual equivaldría a la negativa del otorgamiento del beneplácito para el nombramiento del jefe de la misión. En ambos de los casos analizados, el gobierno guatemalteco solicitó a las instancias correspondientes el cambio del

\footnotetext{
${ }^{10}$ México declaró, en septiembre de 2017, persona non grata al embajador de Corea del Norte y lo expulsó del país argumentando su rechazo ante la actividad nuclear de dicho país; en enero de 2018, el gobierno del presidente venezolano Nicolás Maduro declaró persona non grata al embajador de España, tras los comentarios del gobierno de su país sobre la política interna de Venezuela; al día siguiente, como medida "proporcional" y "de reciprocidad", el Gobierno español anunció la declaración de "persona non grata" al embajador de Venezuela en Madrid. En agosto de 2018, el embajador canadiense fue declarado non grato en Arabia Saudita porque Canadá criticó la política saudí en materia de derechos humanos.
} 
funcionario cuestionado, antes de proceder a la declaratoria de persona non grata, pues como ya se señaló, se considera a ésta recurso de última instancia.

\section{Conclusiones}

En la administración del presidente de Guatemala Jimmy Morales se aplicó la declaratoria de persona non grata a dos diplomáticos acreditados en dicho país. Ambos casos fueron polémicos y generaron debate, confluyendo a la Corte de Constitucionalidad donde se establecieron dos posturas: una que sostenía la validez y aplicabilidad de la facultad conferida por el derecho diplomático a los Jefes de Estado y, por otra, la que defendía la obligación de atender el derecho doméstico antes que la normatividad internacional.

La Corte, por convicción jurídica o motivaciones políticas, en ambos casos dictaminó la conminación al Ejecutivo para que resolviera a través de medios diplomáticos los diferendos, particularmente bajo la negociación, y en el caso del Comisionado, inclusive arguyó incumplimiento en cuanto a las formalidades que domésticamente debían haberse seguido para formalizar dicha declaración. Los argumentos son loables, pero soslayan materialmente el hecho que la conducción de la política exterior es, por mandato constitucional, facultad del Presidente, además que una negociación acordada por medios diplomáticos puede ser infructuosa de no existir voluntad de las partes involucradas en el conflicto.

Evidentemente, la posibilidad de declarar persona non grata a diplomáticos acreditados en su jurisdicción es una prerrogativa de los órganos de las relaciones internacionales y no es legítimo argumentar normas internas para derogar aquella norma internacional. Este es el criterio que en los casos analizados sostuvieron el Ejecutivo guatemalteco y los votos disidentes de la Corte Constitucional frente al criterio contrario de la mayoría de este Tribunal.

Cuando se codificó la figura de declaratoria de persona non grata no se asentó condicionante alguna para su ejercicio, todo lo contrario, se estableció, como ya se mencionó, que "El Estado receptor podrá, en cualquier momento y sin tener que exponer los motivos de su decisión comunicar al Estado acreditante que el 
jefe u otro miembro del personal diplomático de la misión es persona non grata". En el caso analizado, la CC invalida el acto por no haberse cumplimentado la normativa doméstica. La posibilidad de que el procedimiento interno rija la forma en que se pueda declarar non grata a un diplomático debe considerarse superada, quizá aplicable antes de la codificación de la norma. Además, hoy no puede ser norma positiva en la medida que la gran mayoría de los Estados han reconocido la primacía del Derecho Internacional y en el caso particular de Guatemala, inclusive se ha constitucionalizado en virtud de lo establecido en el artículo 149 de su Constitución Política que establece que "Guatemala normará sus relaciones con otros Estados, de conformidad con los principios, reglas y prácticas internacionales con el propósito de contribuir al mantenimiento de la paz y la libertad, al respeto y defensa de los derechos humanos, al fortalecimiento de los procesos democráticos e instituciones internacionales que garanticen el beneficio mutuo y equitativo entre los Estados".

\section{Bibliografía}

Aust, A. (2005). Handbook of International Law. Cambridge: Cambridge University Press Ben-Asher, Dror (2000). Human Rights Meet Diplomatic Immunities: Problems and Possible Solutions. Harvard Law School.

Bondía García, D. (2004). Régimen Jurídico de los Actos Unilaterales de los Estados. Barcelona: J.M. Bosch Editor. "Capital de Panamá declara persona 'non grata' a Donald Trump". (2011, 11 de marzo). El Universo. Recuperado de https://www.eluniverso. com/2011/03/11/1/1379/capital-panama-declara-persona-non-gratadonald-trump.html

CC Corte de Constitucionalidad (2017, 27 de agosto) Resolución de Amparo. Expediente. 4179-2017. Recuperado de https://www. uasb.edu.ec/documents/62017/1494568/Resolución+41792017/9d7d3ab0-856b-407f-b9ff-e9f560533781 
CC Corte de Constitucionalidad (2017, 29 de agosto) Resolución de Amparo. Expediente. 4182-2017. Recuperado de https:/www.cicig. org/wp-content/uploads/2017/08/expediente_4182-2017.pdf

CC Corte de Constitucionalidad (2018, 29 de mayo) Resolución de Amparo. Expedientes Acumulados 2198-2018 y 2201-2018. Recuperado de https://www.prensalibre.com/guatemala/justicia/ccordena-que-sea-jimmy-morales-quien-pida-retiro-de-embajador-desuecia-anders-kompass/

CC Corte de Constitucionalidad (2018b, 29 de mayo). Voto RazonadoMagistrada Dina Josefina Ochoa Escribá - 2198-2018 y 2201-2018 - Caso Embajador Reino de Suecia. Recuperado de https://cc.gob. gt/2018/05/30/voto-razonado-magistrada-dina-josefina-ochoaescriba-2198-2018-y-2201-2018-caso-embajador-reino-de-suecia/

CC Corte de Constitucionalidad (2018c, 19 de septiembre) Resolución de Amparo. Expediente 4207-2018. Recuperado de https://republica.gt/ wp-content/uploads/2018/09/AA-4207-2018-FINAL.pdf

CICIG Comisión Internacional Contra la. Impunidad en Guatemala (2006). Acuerdo entre la Organización de Naciones Unidas y el Gobierno de Guatemala relativo al establecimiento de una. Comisión Internacional Contra la Impunidad en Guatemala. Recuperado de https://www. cicig.org/uploads/documents/mandato/cicig_acuerdo.pdf

Convención sobre Funcionarios Diplomáticos (1928). La Habana. Recuperado de https://www.oas.org/juridico/spanish/tratados/a-25. html

D’Aspremont, J. (2009). "Persona Non Grata”. En Wolfrum, R. (ed.) Max Planck Encyclopedia of International Law, pp. 1-9. Recuperado de https://papers.ssrn.com/sol3/papers.cfm?abstract_id=1448767

Dujarric, S. (2017). Statement attributable to the Spokesman for the Secretary-General on Guatemala. August 27. United Nations. Secretary-General. Recuperado de https://www.un.org/sg/en/content/ sg/statement/2017-08-27/statement-attributable-spokesmansecretary-general-guatemala-scroll 
La figura de declatoria de personas non grata en la diplomacia: experiencias de la práctica reciente en Guatemala

Fakhoury, A. (2017). Persona Non Grata: The Obligation of Diplomats to Respect the Laws and Regulations of the Hosting State. Journal of Law, Policy and Globalization, Vol. 57, pp110-121.

Flores Troche, M. (2019). "Uso de la declaración de persona non grata en tiempos de confrontación: un análisis jurídico de las prácticas estatales recientes". Revista Mexicana de Política Exterior. $\mathrm{N}^{\circ}$ 115, enero-abril, 132-155.

García Laguardia, J. (1996). Política y Constitución en Guatemala, la Constitución de 1985 y sus reformas. $4^{\mathrm{a}}$ ed.; Guatemala: Procuraduría de los Derechos Humanos.

Hendrapati, M. (2014) Legal Regime of Persona Non Grata and the Namru-2 Case. Journal of Law, Policy and Globalization, Vol.32, pp- 161-170.

ICJ. International Court of Justice (1980). United States Diplomatic and Consular Staff in Tehran, Judgment. The Hague.

Juárez, E. (2018, 13 de agosto). "Caso Kompass: Minex insiste en expulsión". Diario La Hora. Recuperado de https://lahora.gt/casokompass-minex-insiste-en-expulsion/

Ley de Amparo, Exhibición Personal y de Constitucionalidad (1986).

Decreto 1-86. Recuperado de https:/www.congreso.gob.gt/assets/ uploads/congreso/marco_legal/87f62-1511972760_ley_de_ amparo_exhibicion_personla_y_de_constitucionalidad.pdf

Melo Lecaros, L. (2004). Diplomacia Contemporánea. Teoría y Práctica. Santiago: RIL Editores.

Montepeque, F. (2018, 12 de enero). "Anders Kompass, el embajador incómodo para el gobierno". El Periódico. Recuperado de https:// elperiodico.com.gt/nacion/2018/01/12/anders-kompass-elembajador-incomodo-para-el-gobierno/

Montesquieu, C. (1845). El Espíritu de las Leyes. Tomo I. Madrid: Imprenta de Don Marcos Bueno. 
Naciones Unidas (1947). Asamblea General. Convención sobre los Privilegios e Inmunidades de los Organismos Especializados. Nueva York. (A/RES/II/179).

Órbita TV. (2017, agosto 27) Jimmy Morales explica por qué expulsó a Iván Velásquez. Recuperado de https://www.youtube.com/ watch? $\mathrm{v}=\mathrm{GeMU}-\mathrm{SHScLw}$

Prensa Libre TV. (2017, agosto 27). Presidente Jimmy Morales pide expulsión del jefe de la CICIG, Iván Velásquez [archivo de video]. Recuperado de https://www.youtube.com/watch?v=nKdG3junJrg Pérez-Desoy i Fage, Carles (2013). "La ruptura de las relaciones diplomáticas: una aproximación sistemática con una referencia especial a las consecuencias de la entrada en vigor del tratado de Lisboa en la praxis diplomática". Revista Electrónica de Estudios Internacionales. $\mathrm{N}^{\circ}$ 26, en http://www.reei.org/index.php/revista/ num26/notas/ruptura-relaciones-diplomaticas-una-aproximacionsistematica-con-una-referencia-especial-consecuencias-entradavigor-tratado-lisboa-praxis-diplomatica

Prensa Libre TV. (2018, septiembre 25). Jimmy Morales: CICIG ha llegado a ser una amenaza para la paz en Guatemala [archivo de video]. Recuperado de https://www.youtube.com/watch?v=g0oOvnl4jF0 Pérez de Cuéllar, J. (1997). Manual de Derecho Diplomático. México: Fondo de Cultura Económica.

Sandström, E. (1950) Rapport on Diplomatic Intercourse and Immunities. A/CN.4/91

Secretary of State (2011). Press Statement Hillary Rodham Clinton. Washington. March 19, 2011, en https://2009-2017.state.gov/ secretary/20092013clinton/rm/2011/03/158664.htm

Sheridan, M. B. (March 3, 2011). "Calderon: WikiLeaks caused severe damage to U.S.-Mexico relations". The Washington Post. Recuperado de https:/www.washingtonpost.com/wpdyn/content/article/2011/03/03/AR2011030302853.html

Sierra González, J. (2000). Derecho constitucional guatemalteco. Guatemala: Piedra Santa. 
"Sweden calls back Guatemala ambassador over UN probe tensions". The Local. February 17, 2019. En https://www. thelocal.se/20190217/sweden-calls-back-guatemalaambassador-over-un-probe

Travieso, J. A. (1998). Código de Derecho Internacional. Buenos Aires: Abeledo-Perrot.

United Nations (1958). International Law Commission. Yearbook of the International Law Commission 1957 Volume II. New York. (A/3623). United Nations (1958b). International Law Commission. Yearbook of the International Law Commission 1958 Volume II. New York. (A/ CN.4/117).

United Nations (1962). Conference on Diplomatic Intercourse and Immunities. Official Records. Volume I. Geneva, A/ $\mathrm{CONFJO} / 14$

United Nations (1962b). Conference on Diplomatic Intercourse and Immunities. Official Records. Volume II. New York, A/ CONF.20/14/Add.1

United Nations (1984). International Law Commission. Yearbook of the International Law Commission 1982 Volume II, Part One. New York. (A/CN.4/354).

Villagrán Kramer, F. (2003). Derechos de los tratados. $2^{\mathrm{a}}$ ed.; Guatemala: F\& G.

Villagrán Sandoval, C. A. (2017) Opinión fundamentada sobre la declaración de persona "non-grata" al Comisionado de la Comisión Internacional contra la Impunidad en Guatemala -CICIG- por parte del señor presidente de la República de Guatemala. Centro de Estudios de Derecho. Recuperado de Witiw, E. P. (1988). "Persona non grata: Expelling Diplomats Who Abuse Their Privileges". Journal of International and Comparative Law. New York Law School. Volume 9, Number 2, pp. 345-359. 
Zamora Marroquín, J. R. (2017, agosto 22). Un llamado a la cordura [Página de Facebook]. Recuperado el 29 de julio de 2019 de https://www.facebook.com/joserubenzamoram/ posts $/ 879255362238998$

Cómo citar el artículo: Cerda C, Bonilla P, (2021). La figura de declaratoria de persona non grata en la diplomacia: experiencias de la práctica reciente en Guatemala. Derecho Global, Estudios sobre Derecho y Justicia, VI (17) pp.167-194 https://DOI.org/10.32870/dgedj. v6i17.351 